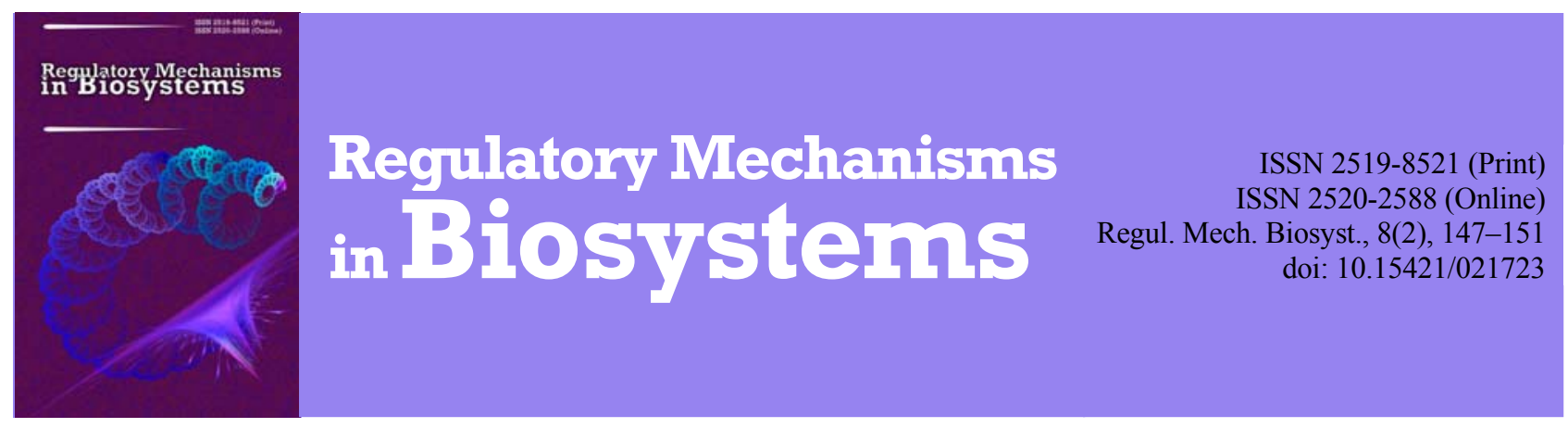

\title{
Hyperhomocysteinemia in patients with chronic kidney disease and its relationship with the functional status of the cardiovascular system
}

\author{
K. P. Postovitenko*, I. A. Iliuk*, S. V. Shevchuk*, G. V. Bezsmertna**, I. O. Bezsmertnyi**, I. V. Kurylenko** \\ *National Pirogov Memorial Medical University, Vinnytsia, Ukraine \\ **Scientific and Research Institute of Invalid Rehabilitation (Educational Scientific Treatment Complex) \\ of National Pirogov Memorial Medical University, Vinnytsia, Ukraine
}

Article info

Received 28.03.2017

Received in revised form 22.04.2017

Accepted 27.04.2017

National Pirogov Memorial Medical University, Vinnytsia, Pirogov Str., 56, Vinnytsia, 21018, Ukraine.

Tel.: +38-043-235-05-63.

E-mail: admission@vnmu.edu.ua

Scientific and Research Institute of Invalid Rehabilitation

(Educational Scientific Treatment Complex) of National Pirogov Memorial Medical University, Khmelnytske Shoes Str., 104 , Vinnytsia, 21029, Ukraine. Tel.: +38-043-243-80-45. E-mail:ins_reab_inv@mail.ru

\section{Introduction}

Nowadays chronic kidney disease (CKD) is a significant medical, social and economic problem. Despite current approaches to treatment, the number of patients with severe CKD continues to rise both in Ukraine and worldwide (Kolesnyk et al., 2016). Such renal pathology dramatically increases the risk and progression of cardiovascular diseases. In particular, the presence of renal dysfunction is a strong independent risk factor for cardiovascular complications (Matsushita et al., 2010; Yildiz et al., 2013; Pang et al., 2016). About $60 \%$ of patients with end-stage renal disease die within one year of acute myocardial infarction (Amin et al., 2010; Fromot et al., 2016) and the risk of further cardiovascular complications is directly proportional to the progression of renal dysfunction (Mazur et al., 2012; Dayal et al., 2014; Lai et al., 2015; Xie et al., in patients with CKD.
Postovitenko, K. P., Iliuk, I. A., Shevchuk, S. V., Bezsmertna, G. V., Bezsmertnyi, I. O., \& Kurylenko, I. V. (2017). Hyperhomocysteinemia in patients with chronic kidney disease and its relationship with the functional status of the

Chronic kidney disease (CKD) is an important medical, social and economic problem nowadays. Patients with causes and pathogenesis of cardiovascular complications are not well understood. One of the recently recognized "nonmild $\mathrm{HHC}$ was observed in 30 (24.4\%) and moderate $\mathrm{HHC}$ - in 33 (26.8\%) cases, i.e. the total number of patients with (t)

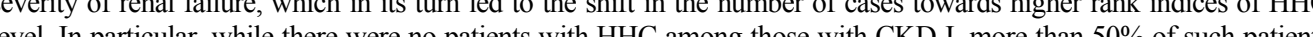
were found in the group with CKD-V. Reduced myocardial contractility and echocardiographic markers of left ventricular hypertrophy in patients with CKD were found to be closely associated with $\mathrm{HC}$ concentrations in blood $\mathrm{HC}$ level. So, the endothelium-dependent brachial artery vasodilation in patients with CKD-IV was lower by 3.8 and compared with control group and CKD-III group, respectively, and endothelium-independent vasodilation of the brachial artery - by 2.4 and 1.9 times, respectively. Correlation analysis also confirmed that impaired endotheliumdependent and endothelium-independent dilation with high statistical significance inversely correlated with the level of in blood plasma. Thus, the population of patients with CKD is characterized by high $\mathrm{HHC}$ frequency, which is myocardium) and can be an important risk factor for the development of vascular lesions. We believe that adequate correction of HHC, including administration of folic acid preparations could reduce the progression of vascular lesions

Keywords: homocysteine; renal failure; left ventricular hypertrophy; myocardial contractile function; endothelial dysfunction

2015). In spite of inevitable risks, the causes and pathogenesis of cardiovascular complications are not fully understood. One of the recently recognized "non-traditional" risk factors of anincreased development of cardiovascular diseases in severe CKD stagesis is hyperhomocysteinemia (HHC) (Chuang et al., 2013; Qin et al., 2013; Baszczuk et al., 2014; Levi et al., 2014). Although many investigations have been devoted to the problem of HHC in CKD (Kolarz et al., 2012; Kolarz et al., 2013; Neigwekar et al., 2015; Zhang et al., 2015; Hang et al., 2016; Toda and Okamura, 2016; Heilman et al., 2017), a number of questions remain insufficiently clarified. Frequency of HHC depending on CKD stageis still unknown. It hasn't been found yet to what extent HHC is associated with other laboratory manifestations of renal failurein patients with CKD, and how it correlates with cardiovascular system status, including endothelial dysfunction. 
In view of this, the aim of the study was to evaluate HHCfrequency in patients with various degrees of CKD and to study its association with endothelial dysfunction and structuralfunctional status of the heart.

\section{Materials and methods}

The observations presented in the work were conducted at Vinnytsia Regional Pirogov Memorial Clinical Hospital, the clinical basis of National Pirogov Memorial Medical University. 148 in-patients and/or outpatients with CKD were examined. All patients gave an informed consent to participate in the study. Chronic glomerulonephritis was diagnosed in 99 (66.9\%) and chronic pyelonephritis - in 49 patients $(33.1 \%)$. There were 77 $(52.0 \%)$ females and $71(48.0 \%)$ males. All patients were divided into two groups: the first one included 113 patients in whom underlying disease was accompanied by decreased glomerular filtration rate (GFR), and the second group consisted of 35 patients with no GFR impairment (CKD-I). In the group of patients with impaired GFR the following stages of CKD were diagnosed: stage II - in 3, stage III - in 43, stageIV - in 14, stage V (terminal) - in 25 patients. The ages of patients in the group with decreased GFR ranged from 18 to 60 years, the average age being $39.6 \pm 1.13$ years. The average age of patients was: $40.3 \pm 2.33$ years in CKD-II group, $45.4 \pm 2.0$ years in CKD-III group, $45.5 \pm 3.38$ years in CKD-IV group and $37.8 \pm 2.53$ yearsin CKD-V group. The average age of patients in CKD-I group was $36.9 \pm 2.4$ years. 30 apparently healthy individuals (14 men and 16 women) aged $21-57$ years (average age $40.6 \pm 2.38$ years) served as representative control group. The stage of $\mathrm{CKD}$ was determined according to the classification adopted by the Second Ukrainian Congress of Nephrologists (2005). Total blood plasma HC level was determined by immunoenzyme method using "Axis-Shield" set (UK) on immunoenzyme analyzer "Santinaile". All subjects underwent echocardiography (EchoCG) studies to determine the carotid intima-media complex (IMC) on ultrasound system "Acuson 128 $\mathrm{XP} / 10$ " (Japan) with $7.5 \mathrm{MHz}$ linear transducer with phase array according to recommendations of the American Echocardiographic Society. Endothelial dysfunction was determined by D. Celermajer's method, described in 1986. The study was carried out in compliance with the provisions of the Council of Europe Convention on Human Rights and Biomedicine, Declaration of Helsinki and recommendations of the Committee on Bioethics of the Presidium of National Academy of Medical Sciences of Ukraine. Statistical analysis of the obtained data was performed with application package Statistica v6.0 (StatSoft Inc., USA). Nonparametric MannWhitney U-test was used to assess the difference between groups, Pearson correlation analysis - to determine the relationships between the indices, Fisher's test - to compare the frequency of changes. $\mathrm{P}<$ 0.05 was considered to be significant difference.

\section{Results}

General information as to $\mathrm{HC}$ level in the studied individuals and ranking by $\mathrm{HC}$ concentration indices, carried out according to the recommendations of Jacobcen (1998) are given in Table 1. HC concentration below $10 \mathrm{mcmol} / \mathrm{l}$ was considered normal and $10-15 \mathrm{mcmol} / \mathrm{l}-$ high normal (subnormal). Mild, moderate and severe HHC was diagnosed at $\mathrm{HC}$ levels $15-25,25-50$ and above $50 \mathrm{mcmol} / \mathrm{l}$, respectively.

Table 1

Total blood plasma homocysteine levelin patients with different stages of $\mathrm{CKD}(\mathrm{M} \pm \mathrm{m})$ and healthy individuals. Ranking of HCconcentrations

\begin{tabular}{|c|c|c|c|c|c|c|}
\hline \multirow{3}{*}{$\begin{array}{l}\text { Group } \\
\text { No }\end{array}$} & \multirow{3}{*}{ Examined individuals } & \multirow{3}{*}{$\begin{array}{l}\text { Homocysteine level, } \\
\mathrm{mcmol} / 1\end{array}$} & \multicolumn{4}{|c|}{ Homocysteine level ranking, number of patients $(\%)$} \\
\hline & & & \multirow{2}{*}{$\begin{array}{c}\text { normal level }<10.0, \\
\mathrm{mcmol} / 1\end{array}$} & \multirow{2}{*}{$\begin{array}{l}\text { subnormal level 10-15, } \\
\mathrm{mcmol} / 1\end{array}$} & \multicolumn{2}{|c|}{ homocysteine } \\
\hline & & & & & mild $15-25, \mathrm{mcmol} / 1$ & $\begin{array}{l}\text { moderate and severe } \\
>25 \mathrm{mcmol} / 1\end{array}$ \\
\hline 1 & practically healthy, $n=30$ & $9.4 \pm 0.57$ & $24(80.0 \%)$ & $4(13.3 \%)$ & $2(6.7 \%)$ & 0 \\
\hline 2 & $\mathrm{CKD}-\mathrm{I}, \mathrm{n}=35$ & $10.7 \pm 0.72$ & $17(48.6 \%)^{*}$ & $10(28.6 \%)^{*}$ & $8(22.8 \%)^{*}$ & 0 \\
\hline 3 & $\mathrm{CKD}-\mathrm{II}, \mathrm{n}=31$ & $15.4 \pm 1.45^{* \#}$ & $6(19.4 \%)^{* \#}$ & $16(51.6 \%)^{* \#}$ & $5(16.1 \%)^{*}$ & $4(12.9 \%)$ \\
\hline 4 & CKD - III, $n=43$ & $21.9 \pm 0.43 * \# \$$ & $3(7.0 \%)^{* \#}$ & $6(14.0 \%) \# \$$ & $14(32.5 \%) * \# \$$ & $20(46.5 \%) \$$ \\
\hline 5 & $\mathrm{CKD}-\mathrm{IV}, \mathrm{n}=14$ & $26.7 \pm 2.10 * \# \$$ & 0 & $2(14.3 \%) \# \$$ & $3(21.4 \%) \$^{\wedge}$ & $9(64.3 \%) \$$ \\
\hline
\end{tabular}

Notes: * - significanceof differences with the group of healthy individuals; \# - significance of differences with the group of patients with CKD-I; $\$-$ significance of differences with the group of patients with CKD-II; ${ }^{\wedge}-$ significance of differences with the group of patients with CKD-III. The mark is indicated only in case of significant differences $(\mathrm{P}<0.05)$.

Severe HHC was not detected in any of the studied patients. Similarly no cases of normal HC level were observed in patients with stage four CKD, i.e. elevated $\mathrm{HC}$ levels were detected in $100 \%$ of patients in this group. It should be noted that even among apparently healthy control individuals 6 out of 30 persons $(20 \%)$ had elevated $\mathrm{HC}$ levels, mild $\mathrm{HHC}$ being determined in 2 cases. Increase of blood plasma $\mathrm{HC}$ levels was virtually proportional to the severity of CKD, which led to the shift in the number of HHC cases towards higher $\mathrm{HC}$ concentrations. Among all patients (123 person) normal and subnormal $\mathrm{HC}$ levelwas determined in 26 $(21.1 \%)$ and $34(27.7 \%)$ cases, respectively; mild and moderate $\mathrm{HHC}$ was found in $30(24.4 \%)$ and $33(26,8 \%)$ cases, respectively.

Baseline values of $\mathrm{HC}$ level in dialysis patients, the control group and the patients with no GFR impairment are given in Table 2.

The analysis of received data revealed the total HClevel in patients with terminal CKD to be almost 3 times as higher than in the group of apparently healthy individuals and 2.5 times higher than in the patients without signs of renal failure. At the same time, there was onlyone person among the dialysis patients with subnormal HC level. No cases of moderate and severe HHC were found in the control group and in the patients with CKD-I, whereas there were $13(52 \%)$ such cases among the dialysis patients. In the next phase of our study we evaluated the structural and functional status of the heart in patients with different CKD stages (Table 3). It was found that in CKD there were changes in a number of echocardiographic indices, whereas the patients without impaired renal functioneither had unchanged indices when compared with healthy people or the changes were insignificant. The increase of CKD stage was followed by the progression of changes in heart ultrasound indices.

During the the next phase of the study the correlation of structural and functional heart status with serum $\mathrm{HC}$ level was evaluated (Table 4).

Elevated HC levelwas proved to be associated with lower ejection fraction. In the patients with $\mathrm{CKD}$ and subnormal $\mathrm{HC}$ level ejection fraction was by $8.2 \%$ lower and continued to decrease with the increase of $\mathrm{HC}$ level - by $14.9 \%$ and $17.8 \%$. Paired correlation analysis showed strong correlation of EF value and blood $\mathrm{HC}$ concentration: correlation coefficient for these indices was negative $(r=-0.5)$. Although no changes of LVPWTd and IVSTd indices insubnormal $\mathrm{HC}$ levels were seen, later they increased significantly with the increase of blood $\mathrm{HC}$ levels, confirmed by close significant correlative relationships between the markers of left ventricular hypertrophy and $\mathrm{HC}$ level ( $\mathrm{r}=0.57$ and 0.59 , respectively). The changes in LVMMI were evident even in subnormal HC level (by $23.3 \%$ ), and they continued to increase proportionally to the increase of $\mathrm{HC}$ concentration to $64.1 \%$ in patients with mild $\mathrm{HHC}$ 
and $96.1 \%$ in those with moderate HHC as compared to people swith normal HC level. There were significant differences in LVMMI value not only in the subjects with normal $\mathrm{HC}$ level, but also among those who had $\mathrm{HHC}$ of various degrees (in all cases $\mathrm{P}<$ 0.05 with paired correlation coefficient 0.58 ). The endothelial function of the patients with different CKD stages (II-V) was determined in the study as well. Functional status of the endothelium was identified in 109 persons, including 20 apparently healthy individuals, 18 patients without signs of renal failure and 71 patients with CKD. The data obtained are presented in Table 5.

Table 2

Total blood plasma homocysteine level in dialysis patients, control group and patients with no GFR impairment(M $\pm \mathrm{m})$

\begin{tabular}{|c|c|c|c|c|c|}
\hline \multirow{3}{*}{ Examined persons } & \multirow{3}{*}{$\begin{array}{l}\text { Homocysteine level, } \\
\mathrm{mmol} / \mathrm{l}\end{array}$} & \multicolumn{4}{|c|}{ Homocysteine level ranking, number of patients, $\%$} \\
\hline & & normal level & subnormal level & & mocysteine \\
\hline & & $<10.0 \mathrm{mcmol} / 1$ & $10-15 \mathrm{mcmol} / 1$ & mild $15-25 \mathrm{mcmol} / \mathrm{l}$ & moderateand severe $>25 \mathrm{mcmol} / 1$ \\
\hline Apparently healthy, $\mathrm{n}=30$ & $9.4 \pm 0.57$ & $24(80.0 \%)$ & $4(13.3 \%)$ & $2(6.7 \%)$ & 0 \\
\hline $\mathrm{CKD}-\mathrm{I}, \mathrm{n}=35$ & $10.7 \pm 0.72$ & $17(48.6 \%)^{*}$ & $10(28.6 \%)^{*}$ & $8(22.8 \%)^{*}$ & 0 \\
\hline $\mathrm{CKD}-\mathrm{V}, \mathrm{n}=25$ & $27.3 \pm 1.83 * \#$ & 0 & $1(4.0 \%) \#$ & $11(44.0 \%)^{*}$ & $13(52.0 \%)$ \\
\hline
\end{tabular}

Notes: * - significance of differences with the group of healthy individuals; \#- significance of differences with the group of patients with CKD - I. The mark is indicated only in case of significant differences $(\mathrm{P}<0.05)$.

Table 3

Echocardiography indices in the group of apparently healthy individuals and in the patients with different stages of $\mathrm{CKD}(\mathrm{M} \pm \mathrm{m})$

\begin{tabular}{|c|c|c|c|c|c|}
\hline \multirow{2}{*}{ Indices } & \multicolumn{5}{|c|}{ Groups } \\
\hline & healthy persons, $n=20$ & $\mathrm{CKD}-\mathrm{I}, \mathrm{n}=18$ & CKD-II, $n=25$ & CKD-III, $n=32$ & CKD-IV, $n=14$ \\
\hline Homocysteine, $\mathrm{mcmol} / \mathrm{l}$ & $9.8 \pm 0.77$ & $10.0 \pm 0.99$ & $15.8 \pm 1.72 * \#$ & $21.9 \pm 1.23 * \# \$$ & $26.8 \pm 2.10 * \# \$$ \\
\hline EDS, mm & $47.7 \pm 0.70$ & $47.8 \pm 0.70$ & $49.4 \pm 0.60$ & $50.9 \pm 0.70 * \#$ & $53.8 \pm 2.10 * \#$ \\
\hline $\mathrm{ESS}, \mathrm{mm}$ & $32.2 \pm 1.12$ & $32.4 \pm 1.03$ & $34.9 \pm 1.73$ & $38.6 \pm 0.77 * \#$ & $40.5 \pm 2.34 * \# \$$ \\
\hline LVPWTd, mm & $9.1 \pm 0.20$ & $9.3 \pm 0.30$ & $10.4 \pm 0.40$ & $12.4 \pm 0.50 * \# \$$ & $13.5 \pm 0.67 * \# \$$ \\
\hline IVSTd, mm & $9.1 \pm 0.30$ & $9.0 \pm 0.35$ & $10.1 \pm 0.40$ & $12.2 \pm 0.48 * \# \$$ & $13.3 \pm 0.70 * \# \$$ \\
\hline LVMM, g & $174 \pm 9$ & $176 \pm 10$ & $220 \pm 14^{*} \#$ & $312 \pm 22 * \# \$$ & $394 \pm 46^{*} \# \$$ \\
\hline $\mathrm{EDV}, \mathrm{ml}$ & $103 \pm 4$ & $105 \pm 4$ & $129 \pm 3 * \#$ & $136 \pm 4 * \#$ & $164 \pm 20 * \#$ \\
\hline $\mathrm{ESV}, \mathrm{ml}$ & $35.2 \pm 2.12$ & $35.6 \pm 2.01$ & $52.5 \pm 2.47 * \#$ & $60.2 \pm 3.66^{* \#}$ & $87.4 \pm 16.70 * \#$ \\
\hline LVMMI, g/cm² & $101 \pm 5$ & $102 \pm 6$ & $128 \pm 8 * \#$ & $180 \pm 13 * \# \$$ & $229 \pm 25^{*} \# \$$ \\
\hline $\mathrm{EF}, \%$ & $66.4 \pm 1.10$ & $66.2 \pm 1.18$ & $59.2 \pm 1.48$ & $56.8 \pm 1.79 * \#$ & $49.2 \pm 2.82 * \# \$^{\wedge}$ \\
\hline RWT, mm & $0.38 \pm 0.01$ & $0.38 \pm 0.01$ & $0.41 \pm 0.01$ & $0.48 \pm 0.02 * \# \$$ & $0.50 \pm 0.02 * \# \$$ \\
\hline $\mathrm{SV}, \mathrm{ml}$ & $68.2 \pm 2.24$ & $69.3 \pm 3.01$ & $76.3 \pm 2.00$ & $76.2 \pm 1.82$ & $78.0 \pm 4.46$ \\
\hline
\end{tabular}

Notes: EDS - end-diastolic size; ESS - end-systolic size; LVPWTd - Left ventricular posterior wall thickness in diastole; IVSTd - interventricular septum thickness in diastole; LVMM - left ventricular muscle mass; EDV - end diastolic volume; ESV - end systolic volume; LVMMI - left ventricular muscle mass index; EF - ejection fraction; RWT - relative wall thickness; SV - stroke volume; * - significance of differences with the group of healthy individuals; \# significance of differences with the group of patients with CKD-I; $\$-$ significance of differences with the group of patients with CKD-II; ${ }^{\wedge}-$ significance of differences with the group of patients with CKD-III. The mark is indicated only in case of significant differences $(\mathrm{P}<0.05)$.

Table 4

Echocardiography indices depending on homocysteinelevel in studied persons $(\mathrm{M} \pm \mathrm{m})$

\begin{tabular}{|c|c|c|c|c|c|}
\hline \multirow{3}{*}{ Indices } & \multicolumn{4}{|c|}{ Homocysteine, $\mathrm{mcmol} / \mathrm{l}$} & \multirow{3}{*}{$\mathrm{r}$} \\
\hline & \multirow{2}{*}{$\begin{array}{c}\text { normal level } 7.8 \pm 0.23 \text {, } \\
n=35\end{array}$} & \multirow{2}{*}{$\begin{array}{c}\text { subnormal level } 13.2 \pm 0.25 \\
\mathrm{n}=25\end{array}$} & \multicolumn{2}{|c|}{ hyperhomocystenimia } & \\
\hline & & & mild $18.8 \pm 0.72, \mathrm{n}=21$ & moderate and severe $30.0 \pm 0.63, \mathrm{n}=28$ & \\
\hline $\mathrm{EDS}, \mathrm{mm}$ & $47.9 \pm 0.46$ & $49.6 \pm 0.72$ & $49.9 \pm 0.95$ & $52.3 \pm 1.10 \#$ & $0.39 *$ \\
\hline ESS, mm & $32.6 \pm 0.81$ & $36.3 \pm 0.91$ & $35.6 \pm 2.11$ & $39.5 \pm 1.34 \#$ & $0.31 *$ \\
\hline LVPWTd, mm & $9.2 \pm 0.30$ & $10.2 \pm 0.40$ & $12.1 \pm 0.58 \#$ & $12.9 \pm 0.51 \# \$$ & $0.57 *$ \\
\hline IVSTd, mm & $9.0 \pm 0.30$ & $10.1 \pm 0.39$ & $12.0 \pm 0.50 \#$ & $12.7 \pm 0.52 \# \$$ & $0.59 *$ \\
\hline LVMM, g & $176 \pm 9.8$ & $220 \pm 14.6 \#$ & $295 \pm 27.5 \#$ & $349 \pm 28.5 \# \$^{\wedge}$ & $0.58^{*}$ \\
\hline $\mathrm{EDV}, \mathrm{ml}$ & $187 \pm 3.5$ & $123 \pm 2.9 \#$ & $132 \pm 6.1$ & $149 \pm 10.7 \#$ & $0.42 *$ \\
\hline $\mathrm{ESV}, \mathrm{ml}$ & $37.6 \pm 2.08$ & $49.0 \pm 2.68 \#$ & $59.2 \pm 4.41 \#$ & $72.3 \pm 9.14 \#$ & $0.45^{*}$ \\
\hline LVMMI, g/cm² & $103 \pm 5.5$ & $127 \pm 7.9 \#$ & $169 \pm 15.1 \#$ & $202 \pm 16.4 \# \mathbb{\$}^{\wedge}$ & $0.58^{*}$ \\
\hline $\mathrm{EF}, \%$ & $65.8 \pm 0.99$ & $60.4 \pm 1.78 \#$ & $56.0 \pm 1.66 \#$ & $54.1 \pm 2.17 \# \$$ & $-0.50 *$ \\
\hline RWT, mm & $0.38 \pm 0.010$ & $0.41 \pm 0.017$ & $0.48 \pm 0.010 \# \$$ & $0.49 \pm 0.010 \# \$$ & $0.54^{*}$ \\
\hline $\mathrm{SV}, \mathrm{ml}$ & $70.5 \pm 1.89$ & $74.0 \pm 2.47$ & $73.3 \pm 2.25$ & $78.2 \pm 2.46$ & 0.21 \\
\hline
\end{tabular}

Notes: \# - significance of differences with the group of persons with normal HC level (1); $\$$ - significance of differences with the group of patients with subnormal $\mathrm{HC}$ level $(2) ;^{\wedge}-$ significance of differences with the group of patients with mild HHC (3); ${ }^{*}$ - correlation significance. The mark is indicated only in case of significant differences $(\mathrm{P}<0.05)$.

There were no differences in the initial flow velocity rate in all studied patients and apparently healthy control group. In the patients with CKD - I only endothelium-dependent dilation index was decreased, indicating the presence of patients in this group with early signs of endothelial dysfunction.

More significant changes of endothelial function were found in the patients with $\mathrm{CKD}$ - II. Both the initial diameter of the brachial artery $\left(\mathrm{D}_{0}\right)$ and its diameter in 60 seconds after removing the cuff were higher compared to the control. Besides, significantly decreased EDVDBA was observed in those patients. Thus, the patients with CKD - II had more pronounced signs of endothelial dysfunction as compared to the patients with CKD - I. In the patients with CKD - III disturbances of EDVDBA and EIDVBA were detected (in 2.2 and 1.3 times, respectively), indicative of more significant vascular endothelial dysfunction: there was inhibition of both nitric oxide synthesis and the reception of this endothelium-derived relaxing factor. Thus, in the patients with CKD - IV further progression of endothelial dysfunction was observed. In patients with CKD - IV the diameter of the brachial artery proved to be the largest and both types of dilatation were the least amongall studied persons $(\mathrm{P}<0.05)$. In comparison with the control group and the CKD-III group, EDVDBA was lower in 3.8 and 1.5 times, respectively, and EIVDB - in 2.4 and 1.9 times, respectively, indicating further inhibition of endothelial nitric oxide 
synthesis as well as its vasodilatory activity. Absolute and relative number of patients with the signs of endothelial dysfunction was found to increase with the increase of CKD severity stage. So, the number of these patients reached $78 \%$ by EDVDBA index and $64.3 \%$ by EIVDBA index from the group with CKD - II to the group with CKD - IV. It is essential to note that there were no cases of decreased endothelium-independent dilation without simultaneous decrease of endothelium-dependent dilation.

Comparison of groups of patients matched byHC level (normal, subnormal and increased - mild and moderate HHC), with endothelial function indices (Table 6), revealed that the initial diameter of the brachial artery in reactive hyperemia phase, initial blood flow velocity and its increase rate were similar in all groups, i.e. they were independent of the $\mathrm{HC}$ levels. Only two values - endothelium-dependent and endothelium-independent dilation - decreased inversely proportional to theincrease of blood plasma $\mathrm{HC}$ level, suggesting possible pathogenetic relationship between increased blood plasma HC concentration and vascular endothelial dysfunction. The initial diameter of the brachial artery as well as its diameter in the phase of reactive hyperemia correlated with $\mathrm{HC}$ level only in CKD-II and CKD - III, and blood flow velocity rate in the reactive hyperemia phase - only in CKD - III. As to the main parameters of endothelial function - endothelium-dependent and endothelium-independent dilation, their decrease inversely correlated with high statistical significance (in all cases $t>3$ ) with blood plasma HC level in CKD - II, CKD - III and CKD - IV (for endothelium-dependent dilation) and with CKD - III and CKD - IV (for endothelium-independent dilation).

\section{Table 5}

Endothelial dysfunction indices in patients with different stages of CKD $(\mathrm{M} \pm \mathrm{m})$ and their association with HC level

\begin{tabular}{|c|c|c|c|c|c|}
\hline \multirow{2}{*}{ Indices } & \multicolumn{5}{|c|}{ Studied groups } \\
\hline & control, $\mathrm{N}=20$ & $\mathrm{CKD}-\mathrm{I}, \mathrm{n}=18$ & $\mathrm{CKD}-\mathrm{II}, \mathrm{n}=25$ & CKD - III, $n=32$ & $\mathrm{CKD}-\mathrm{IV}, \mathrm{n}=14$ \\
\hline $\mathrm{D}_{0}, \mathrm{~mm}$ & $3.61 \pm 0.16$ & $4.09 \pm 0.20$ & $4.41 \pm 0.18^{*}$ & $3.93 \pm 0.12$ & $4.44 \pm 0.19^{* \wedge}$ \\
\hline $\mathrm{D}_{60}, \mathrm{~mm}$ & $4.14 \pm 0.20$ & $4.52 \pm 0.23$ & $4.88 \pm 0.24^{*}$ & $4.19 \pm 0.13$ & $4.68 \pm 0.23$ \\
\hline $\mathrm{V}_{0}, \mathrm{~m} / \mathrm{c}$ & $0.58 \pm 0.02$ & $0.67 \pm 0.03$ & $0.64 \pm 0.02$ & $0.60 \pm 0.01$ & $0.58 \pm 0.02 \#$ \\
\hline Endothelium-dependent dilation, $\%$ & $14.3 \pm 1.15$ & $10.3 \pm 1.20^{*}$ & $9.8 \pm 1.15^{*}$ & $6.6 \pm 0.64 * \# \$$ & $4.4 \pm 1.08 * \# \mathbb{\$}^{\wedge}$ \\
\hline Proportion of persons with decreased EDVDBA & - & $8(44.4 \%)$ & $14(56.0 \%)$ & $24(75.0 \%) \#$ & $11(78.0 \%) \#$ \\
\hline Endothelium-independent dilation, $\%$ & $19.0 \pm 1.25$ & $16.5 \pm 1.43$ & $18.9 \pm 1.37$ & $14.5 \pm 1.09 * \$$ & $7.8 \pm 1.00^{*} \# \$^{\wedge}$ \\
\hline Proportion of persons with decreased EIDVBA & - & $3(16.7 \%)$ & $4(16.0 \%)$ & $9(28.0 \%)$ & $9(64.3 \%) \#$ \\
\hline Blood flow velocity rate, $\%$ & $163 \pm 9.9$ & $137 \pm 10.4$ & $140 \pm 9.7$ & $142 \pm 8.7$ & $155 \pm 10.3$ \\
\hline
\end{tabular}

Notes: $\mathrm{D}_{0}$ - initial diameter of the brachial artery; $\mathrm{D}_{60}-$ the diameter of the brachial artery in 60 seconds after cuff removal; $\mathrm{V}_{0}-$ initial blood flowrate; EDVDBA - endothelium-dependent vasodilation of brachial artery; EIDVBA - endothelium-independent vasodilation of brachial artery; * - significance of differences with the group of healthy individuals; \# - significance of differences with the group of patients with CKD - I; $\$$ - significance of differences with the group of patients with $\mathrm{CKD}-\mathrm{II},{ }^{\wedge}$ - significance of differences with the group of patients $\mathrm{CKD}-\mathrm{II}$. The mark is indicated only in case of significant differences $(\mathrm{P}<0.05)$.

Table 6

Endothelial function indicesin different blood plasma $\mathrm{HC}$ levels $(\mathrm{M} \pm \mathrm{m})$

\begin{tabular}{|c|c|c|c|c|}
\hline \multirow{3}{*}{ Indices } & \multicolumn{4}{|c|}{ Ranking of HC levels } \\
\hline & \multirow{2}{*}{$\begin{array}{c}\text { normal level } \\
<10.0 \mathrm{mcmol} / 1 \\
\mathrm{n}=37\end{array}$} & \multirow{2}{*}{$\begin{array}{c}\text { subnormal level } \\
10-15 \mathrm{mcmol} / \mathrm{l} \\
\mathrm{n}=28\end{array}$} & \multicolumn{2}{|c|}{ hyperhomocysteinemia } \\
\hline & & & $\begin{array}{l}\text { mild } 15-25 \mathrm{mcmol} / \mathrm{l} \\
\mathrm{n}=20\end{array}$ & $\begin{array}{l}\text { moderate and severe }>25 \mathrm{mcmol} / 1, \\
\mathrm{n}=24\end{array}$ \\
\hline Homocysteine, mcmol/l & $7.9 \pm 0.21$ & $12.9 \pm 0.28$ & $19.8 \pm 0.70$ & $29.9 \pm 0.62$ \\
\hline $\mathrm{D}_{0}, \mathrm{~mm}$ & $4.14 \pm 0.15$ & $4.32 \pm 0.15$ & $3.58 \pm 0.14$ & $4.09 \pm 0.13$ \\
\hline $\mathrm{D}_{60}, \mathrm{~mm}$ & $4.72 \pm 0.17$ & $4.80 \pm 0.19$ & $3.77 \pm 0.15$ & $4.24 \pm 0.13$ \\
\hline $\mathrm{V}_{0}, \mathrm{~m} / \mathrm{c}$ & $0.63 \pm 0.02$ & $0.66 \pm 0.02$ & $0.57 \pm 0.02$ & $0.58 \pm 0.02$ \\
\hline Endothelium-dependent dilation, \% & $13.7 \pm 0.80$ & $10.1 \pm 0.77 *$ & $5.5 \pm 0.76^{* \#}$ & $3.8 \pm 0.57 * \#$ \\
\hline Endothelium-independent dilation, $\%$ & $19.3 \pm 0.84$ & $18.5 \pm 1.06$ & $11.9 \pm 1.22 * \#$ & $10.5 \pm 1.42 * \#$ \\
\hline Blood flow velocity rate, $\%$ & $159 \pm 7.5$ & $143 \pm 9.2$ & $136 \pm 9.8$ & $138 \pm 8.9$ \\
\hline
\end{tabular}

Notes: * - significance of differences with the group of persons with normal HC level (1); \# - significance of differences with the group of persons with subnormal HC levels (2). The mark is indicated only in case of significant differences $(\mathrm{P}<0.05)$.

\section{Discussion}

Thus, the investigation of blood plasma $\mathrm{HC}$ level in the patients with CKD showed normal and subnormal HC levels in $26(21.1 \%)$ and 34 persons $(27.7 \%)$, respectively; mild and moderate HHCwas found in $30(24.4 \%)$ and $33(26.8 \%)$ cases, respectively, i.e. the total number of patients with elevated HC level was $88.9 \%$. It should be noted that no patients with normal $\mathrm{HC}$ level were found in CKD-IV group as well as among dialysis patients.

The increase of blood plasma HC level was virtually proportional to the severity of renal failure, which in its turn led to the shift in the number of cases towards higher rank indices of HHC level. In particular, while no patients with $\mathrm{HHC}$ were found among those with CKD - I, there were more than $50 \%$ of such cases in the group with $\mathrm{CKD}-\mathrm{V}$. HC accumulation in patients with renal damage is quite understandable, because it is the kidneys that play the major role in HC elimination from blood plasma (Long and Nie, 2016). On the other hand, high levels of HC may in their turn aggravate kidney damage as renal vascular endothelium is highly sensitive to the toxic effects of excessive HC.
The data obtained suggest that adverse structural and functional changes in the heart and blood vessels are associated with an increase of serum HC levels. In particular, increased HC levels were associated with lower ejection fraction (EF) indices. Correlation coefficient was $-0.5(\mathrm{P}<0.05)$, indicative of progressive reduction of myocardial contractile function, it depending on the increase of $\mathrm{HC}$ levelas well as CKD stage. The indices being actually the markers of left ventricular hypertrophy (LVPWTd, IVSTd and LVMMI) increased significantly with the increase of blood HC levels which was confirmed by strong significant correlation relationships between them.

Tge ability of $\mathrm{HC}$ to affect adversely the structural and functional status of the heart was previosly demonstrated in the patients with coronary artery disease (Gangly and Alam, 2015) as well as in patients with CKD in clinical settings and experimental conditions (Tyagi et al., 2005).

The data presented clearly demonstrate that endothelial dysfunction indices exhibit strong inverse correlation with $\mathrm{HC}$ level. EDVDBA was lower in 3.8 and 1.5 times, respectively, and EIDVBA - in 2.4 and 1.9 times, respectively, in CKD - IV group compared with the control and CKD - III group. Correlation analy- 
sis also confirmed that impaired endothelium-dependent and endothelium-independent dilation inversely correlated with blood plasma HC level with high statistical significance (in all cases $\mathrm{t}>3$ ). The relationship between endothelium-dependent and endotheliumindependent dilation and the degree of renal failure was described in other trials (Rebrov and Zalepukina, 2001; Lai and Kan, 2015) but HHC role as a factor of vascular lesions was not studied.

Thus, the population of patients with CKD is characterized by high frequency of $\mathrm{HHC}$, which is closely associated with diseases of the cardiovascular system (endothelial dysfunction, structural and functional myocardium remodelling) and may be an important risk factor for the development ofvascular lesions. We believe that adequate HHC correction, folic acid administration in particular, couldreduce the progression of vascular lesions in patients with CKD.

\section{Conclusions}

In patients with $\mathrm{CKD} \mathrm{HHC}$ occurs with high frequency. The increase of blood plasma $\mathrm{HC}$ level is proportional to the severity of CKD stage. While HHC occurs in $12.9 \%$ of cases in CKD - II, it makes up $46.5 \%$ in CKD - III, $64.3 \%$ - in CKD - IV, $52.5 \%$ - in dialysis patients. Decreased myocardial contractility, left ventricular hypertrophy (LVPWTd, IVSTd and LVMMI) as well as endothelial dysfunction (EDVDBA and EIDVBA) in patients with CKD are closely associated with blood plasma HC concentrations. Adequate $\mathrm{HHC}$ correction, folic acid administration in particular, couldreduce the progression of vascular lesions in patients with CKD.

\section{References}

Amin, A. P., Spertus, J. A., Reid, K. J., Lan, X., Buchanan, D. M., Decker, C., \& Masoudi, F. A. (2010). The prognostic importance of worsening renal function during an acute myocardial infarction on long-term mortality. American Heart Journal, 60, 1065-1071.

Baszczuk, A., Kopczynski, Z., \& Thielemann, A. (2014). Endothelial dysfunction in patients with primary hypertension and hyperhomocysteinemia. Postepy Higieny i Medycyny Doswiadczainej, 68, 91-100.

Chuang, C. H., Lee, Y. Y., Sheu, B. F., Hsiao, C. T., Loke, S. S., Chen, J. C., \& Li, W. C. (2013). Homocysteine and C-reactive protein as useful surrogate markers for evaluating CKD risk in adults. Kidney Blood Pressure Research, 37, 402-413.

Dayal, S., Blokhin, I. O., Erger, R. A., Jensen, M., Arning, E., Stevens, J. W., Bottiglieri, T., Faraci, F. M., \& Lentz, S. R. (2014). Protective vascular and cardiac effects of inducible nitric oxide synthase in mice with hyperhomocysteinemia. PLoS One, 9(9), e107734.

Fromot, J., Deharo, P., Bruzzese, L., Cuisset, T., Bonatti, S., Fenouillet, E., Motolla, G., Ruf, J., Guieu, R., \& Can, J. (2016). Adenosine plasma level correlates with homocysteine and uric acid in patients with coronary artery disease. Physiology and Pharmacology, 94(3), 272-277.

Gangly, P., \& Alam, S. F. (2015). Role of homocysteine in the development of cardiovascular disease. Nutrition Journal, 14, 6.

Hang, X., Yuling, Z., Yanjie, X., William, Y., Xiaohua, J., Xiaojin, S., Xiaoshu, C., Jingfeng, W., Xuebin, Q., Jun, Y., Yong, J., Xiaofeng, Y., \& Hong, W. (2017). Caspase-1 inflammasome activation mediates homocysteine-induced pyromapoptosis in endotelial cells. Circulation Research, 118(10), 1525-1539.

Heilmann, R. M., Grutzner, N., Iazbik, M. C., Lopes, R., Bridges, C. S., Suchodolski, J. S., Couto. C. G., \& Steiner, J. M. (2017). Hyperhomocysteinemia in Greyhounds and its association whith hypofolatemia and other clinicopatologic variables. Journal of Veterinary Internal Medicine, 31(1), $109-116$.

Jacobsen, D. W. (1998). Homocysteine and vitamins in cardiovascular disease. Clinical Chemistry, 44, 1833-1843.
Kolarz, M., Glowacki, R., Stompor, T., Wyroslak, J., \& Undas, A. (2012). Elevated levels of $\mathrm{N} \varepsilon$-homocysteinyl-lysine isopeptide in patients on long-term hemodialysis. Clinical Chemistry and Laboratory Medicine, 50(8), 1373-1378.

Kolarz, M., Malyszko, J., Stompor, T., Calca, A., Undas, A., \& Mysliwiec, M. (2013). Antibodies against Ne-homocysteinylated proteins in patients on different methods of renal replacement therapy. Clinical Chemistry and Laboratory Medicine, 51(5), 1093-1099.

Kolesnyk, M., Nicolaenko, S., \& Snisar, L. (2016) Rating score medical care renal profile in Ukraine 2015. Ukrainian Journal of Nephrology and Dialysis, 4(52), 1-9.

Lai, S., Dimko, M., Galani, A., Coppola, B., Innico, G., Frassetti, N., Mazzei, E. D., \& Mariotti, A. (2015). Early markers of cardiovascular risk in chronic kidney disease. Renal Failure, 37(2), 254-261.

Lai, W. K., \& Kan, M. Y. (2015). Homocysteine-induced endothelial dysfunction. Annals of Nutrition and Metabolism, 67(1), 1-12.

Levi, A., Cohen, E., Levi, M., Golberg, E., Garty, M., \& Krause, I. (2014). Elevated serum homocysteine is a predictor of accelerated decline in renal function and chronic kidney disease: A historical prospective study. European Journal of Internal Medicine, 25(10), 951-955.

Long, Y., \& Nie, J. (2016). Homocysteine in renal injury. Kidney Diseases (Basel), 2(2), 80-87.

Matsushita, K., van der Velde, M., Astor, B. C., Woodward, M., Levey, A. S., de Jonq, P. E., Corech, J., \& Gansevoort, R. T. (2010). Association of estimated glomerular filtration rate and albuminuria with all-cause and cardiovascular mortality in general population cohorts: A collaborative meta-analysis. Lancet, 375(9731), 2073-2081.

Mazur, P., Kozynacka, A., Duraiski, L., Glowacki, R., Pfitzner, R., Fijorek, K., Sadovski, J., \& Undas, A. (2012). Ne-homocysteinyl-lysine isopeptide is associated with progression of peripheral artery disease in patients treated with folic acid. European Journal of Vascular and Endovascular Surgery, 43(5), 588-593.

Neigwekar, S. U., Kang, A., Zoungas, S., Cass, F., Gallagher, M. P., Kulshrestha, S., Navaneethan, S. U., Perkovic, V., Strippoli, G. F., \& Jardine, M. J. (2015). Interventions for lowering plasma homocysteine levels in dialysis patients. Cochrane Database of Systematic Reviews, 31(5), CD004683.

Pang, H., Han B., Fu, Q., \& Zong, Z. (2016). Association of high homocysteine levels with the risk stratification in hypertensive patients at risk of stroke. Clinical Therapeutics, 38(5), 1184-1192.

Qin, X., Huo, Y., Xie, D., Hou, F., Xu, X., \& Wang, H. (2013). Homocysteinelowering therapy whith folic acid is effective in cardiovascular disease prevention in patients whith kidney disease: A meta-analysis of randomized controlled trials. Clinical Nutrition, 32(5), 722-727.

Rebrov, A. P., \& Zelepukina, N. Y. (2001). Disfunction an endoteliya at patients with a chronic glomerulonefrit in various stages of a renal failure. Nephrology and Dialysis, 3(4), 33-36.

Toda, N., \& Okamura, T. (2016). Huperhomocysteinemia impairs regional blood flow: Involvements of endothelial and neuronal nitric oxide. Pfugers Archiv, 468(9), 1517-1525.

Tyagi, N., Sedoris, K. S., Steed, M., Ovechkin, A. V., Moshai, K. S., \& Tyagi, S. C. (2005). Mechanisms of homocysteine-induced oxidative stress. American Journal of Physiology Heart and Circulatory Physiology, 289(6), 2649-2656.

Xie, D., Yuan, Y., Guo, J., Yang, S., Xu, X., Wang, Q., Li, Y., Qin, X., Tang, G., Huo, Y., Deng, G., Wu, S., Wang, B., Zhang, Q., Wang, X., Fang, P., Wang, H., Xu, X., \& Hou, F. (2015). Hyperhomocysteinemia predicts renal function decline: A prospective study in hypertensive adults. Scientific Reports, 5, 16268.

Yildiz, G., Duman, A., Aydin, H., Yilmaz, A., Hur, E., Magden, K., Cetin, G., \& Candan, F. (2013). Evaluation of association between atherogenic index of plasma and intima-media thickness of the carotid artery for subclinic atherosclerosis in patients on maintenance hemodialysis. Hemodialysis International, 17(3), 397-405.

Zhang, D., Sun, X., Liu, J., Xie, X., Cui, W., \& Zhu, Y. (2015). Homocysteine accelerates senescence of endothelial cells via DNA hypomethylation of human telomerase reverse transcriptase. Arteriosclerosis, Thrombosis and Vascular Biology, 35(1), 71-78. 